\title{
Control algorithm and energy management strategy for extended range electric tractors
}

\author{
Xu Liyou ${ }^{1}$, Zhang Junjiang ${ }^{1}$, Liu Mengnan ${ }^{1}$, Zhou Zhili ${ }^{1 *}$, Liu Chengqiang ${ }^{2}$ \\ (1. College of Vehicle and Traffic Engineering, Henan University of Science and Technology, Luoyang 471003, China; \\ 2. Shandong Shifeng Group Co., Ltd., Liaocheng 252800, China)
}

\begin{abstract}
It is difficult to make full use of the electrical energy of the power battery for extended-range electric tractors because the battery's state of charge may be relatively high at the end of the running mileage. To address this situation, this paper aimed to study the control parameter adjustment in relation to the power battery's electrical consumption and the diesel engine's fuel consumption energy management strategy. Based on the AVL-Cruise simulation platform, the vehicle model of the tractor was established, and the control module of AVL-Cruise was used to compile the energy management strategy. In order to verify the superiority of the proposed strategy, the contrast strategy was employed in terms of the diesel engine start and stop control plus fixed point energy management strategy (FPEMS). The applicability of the proposed strategy was tested through continuous transfer operation and the small area deep loosening operation. The simulation results show that the proposed strategy was of good applicability. Compared with the FPEMS, the fuel consumption reduced significantly, and the electrical consumption of the power battery increased obviously.
\end{abstract}

Keywords: extended-range electric tractor, parameter adjustment, energy management strategy, simulation analysis DOI: $10.25165 /$ j.ijabe.20171005.2692

Citation: Xu L Y, Zhang J J, Liu M N, Zhou Z L, Liu C Q. Control algorithm and energy management strategy for extended range electric tractors. Int J Agric \& Biol Eng, 2017; 10(5): 35-44.

\section{Introduction}

Traditional tractors with high fuel consumption have high emissions ${ }^{[1-5]}$. Technological difficulties existing in batteries $^{[6-9]}$ prevent their popularization and application in pure electric tractors. With an energy system combining battery and diesel energy, an extended-range electric tractor (ERET) has an improved driving range that prolongs its working time ${ }^{[10-13]}$.

Received date: 2016-07-10 Accepted date: 2017-04-19

Biographies: Xu Liyou, $\mathrm{PhD}$, Professor, research interest: agricultural tractor transmission technology, Email: xlyou2002@ sina.com; Zhang Junjiang, Master Student, research interest: agricultural tractor transmission technology, Email: 1123030291@ qq.com; Liu Mengnan, PhD candidate, research interest: electric technology of off-road vehicle, Email: liumengnan27@163.com;

*Corresponding author: Zhou Zhili: PhD, Professor, research interest: low vehicle transmission technology. Mailing address: No. 263, Kaiyuan Avenue, Luolong District, Luoyang 471003, China. Tel: +86-379-64231912, Email: zzli@haust.edu.cn; Liu Chengqiang, Master, Researcher, research interest: electric vehicle transmission technology, Email: 2499658797@qq.com.
Therefore, it is of great significance to study ERET. Electrical energy can be generated and converted from many types of energy sources like solar energy, wind energy and hydropower ${ }^{[14]}$. Electrical energy from the power grid is widely used in rural areas of China, so increasing the consumption of the battery's energy can reduce diesel consumption and get rid of the dependence on fossil fuel ${ }^{[15]}$.

The goals of energy management strategy in hybrid electric vehicles (HEVs) were to minimize fuel consumption and pollutant emissions. There are mainly two kinds of methods of energy management strategy in HEVs: optimization approach control and rule-based control $^{[16,17]}$. Ansarey et al. $^{[18]}$ adopted multi-dimensional dynamic programming in optimal energy management for a dual-storage fuel-cell hybrid vehicle and obtained maximum reduction in fuel consumption between a single and a double buffer fuel-cell hybrid vehicle in various driving cycles. However, there is a problem called the "curse of 
dimensionality" in multi-dimensional dynamic programming. Hou et al. ${ }^{[19]}$ applied the approximate Pontryagin's Minimum Principle (A-PMP) algorithm to parallel plug-in hybrid electric vehicles, and fuel consumption was reduced by $6.96 \%$, compared with the conventional "All-Electric, Charge-Sustaining" strategy. However, A-PMP algorithm is improperly used in the real-time control, because the calculations of boundary conditions and variable derivations in Hamilton function are complex and difficult. Nuesch et al. ${ }^{[20]}$ conducted equivalent consumption minimization strategy (ECMS) to minimize the fuel consumption of a diesel-electric hybrid vehicle. However, an appropriate formulation is a problem for ECMS. A genetic algorithm and quadratic programming $^{[21]}$ were used in plug-in hybrid electric vehicles to improve engine work efficiency and reduce fuel consumption. But it takes time for a genetic algorithm to deal with a series of operations consisting of crossover, mutation and elite selection, and quadratic programming requires knowledge of the driving conditions beforehand. Rule-based methods ${ }^{[22,23]}$, which are simpler, easier and more reliable than optimization approach control methods, have been widely used by vehicle manufacturers. Fuzzy Logic ${ }^{[24]}$ was used in series hybrid electric vehicles to enhance engine operation efficiency and extend the battery life. But much work must be done to build the fuzzy logic table. Banvait et al. ${ }^{[25]}$ conducted rule-based energy management for a plug-in hybrid electric vehicle. The engine efficiency and gas mileage increased significantly, compared with a parallel control strategy. But energy saving can be further improved, for the state of charge (SOC) of a battery may be relatively high at the end of running mileage.

To address the problem of the SOC at the end of running mileage ${ }^{[25]}$, an energy-management strategy was designed in this study to adjust the energy system parameters of an ERET based on a YTO 1804 tractor model. The strategy's applicability was verified under two operating conditions. The strategy's energy saving effect was also tested, compared with a diesel engine with start-and-stop control plus a fixed-point energy-management strategy (FPEMS).

\section{Powertrain of ERET}

\subsection{Structure and main parameters of the powertrain}

Figure 1 shows the structure of the powertrain of an ERET. The power battery, diesel engine-generator, traction motor, transmission, main reducer, differential, and wheel-side reducer constitute the basic components of the powertrain. The power battery, diesel engine-generator, and traction motor are connected to electricity. The traction motor, transmission, main reducer, differential, and wheel-side reducer are connected mechanically. At the same time, the controller is linked with the diesel engine-generator, power battery, and traction motor by a control link. The design of this powertrain is based on that of a YTO 1804 tractor model ${ }^{[10]}$. Table 1 shows the main parameters of the ERET powertrain.

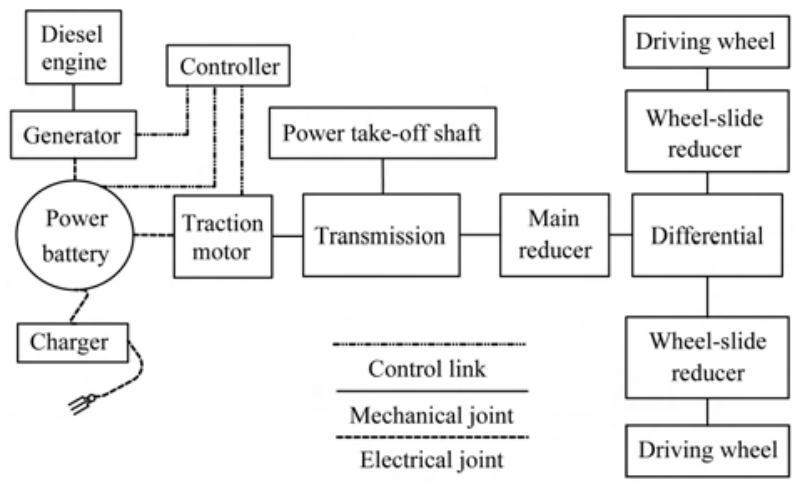

Figure 1 Structure of the powertrain of ERET

Table 1 Main parameters of the ERET powertrain

\begin{tabular}{|c|c|c|}
\hline Components & Parameters & Values \\
\hline \multirow{4}{*}{ Tractor } & Curb weight $/ \mathrm{kg}$ & 7760 \\
\hline & Gross weight $/ \mathrm{kg}$ & 18000 \\
\hline & Wheel base/cm & 2848 \\
\hline & Height of hitch/cm & 80 \\
\hline \multirow{2}{*}{ Diesel engine-generator } & Rated speed $/ \mathrm{r} \cdot \mathrm{min}^{-1}$ & 2400 \\
\hline & Rated power $/ \mathrm{kW}$ & 75 \\
\hline \multirow{3}{*}{ Traction motor } & Rated power $/ \mathrm{kW}$ & 135 \\
\hline & Rated torque $/ \mathrm{N} \cdot \mathrm{m}$ & 430 \\
\hline & Rated speed $/ \mathrm{r} \cdot \min ^{-1}$ & 3000 \\
\hline \multirow{3}{*}{ Power battery } & Nominal voltage/ $\mathrm{V}$ & 320 \\
\hline & Capacity/A $\cdot \mathrm{h}$ & 2800 \\
\hline & Rated output power $/ \mathrm{kW}$ & $>135$ \\
\hline \multirow{4}{*}{ Transmission } & Speed ratio of I gear & 4.99 \\
\hline & Speed ratio of II gear & 4.24 \\
\hline & Speed ratio of III gear & 3.5 \\
\hline & Speed ratio of IV gear & 2.75 \\
\hline Main reducer & Speed ratio & 6.4 \\
\hline Wheel-side reducer & Speed ratio & 4.55 \\
\hline Driving wheel & Rolling radius $/ \mathrm{m}$ & 0.9 \\
\hline Front wheel & Rolling radius $/ \mathrm{m}$ & 0.66 \\
\hline
\end{tabular}




\subsection{Power flow of ERET powertrain}

An ERET powertrain has two energy sources. One is the power battery; the other is an extended range device consisting of a diesel engine-generator. Multiple energy sources provide the possibility for multiple operating modes. The ERET powertrain has three operating modes, consisting of the pure electric drive, extended-range, and parking charging modes.

Figure 2 shows the power flow in pure electric drive mode. The tractor operates in this mode when the power battery's SOC is higher than its minimum threshold, based on the energy management strategy. The electrical power of the power battery is transformed to mechanical power by the traction motor, and then it flows to the transmission. Part of the power is transmitted to the power take-off shaft for the tractor's work, and another part is transmitted to the main reducer. After its deceleration effect, the mechanical power goes through the differential and wheel-side reducer, and finally gets to the driving wheel that is used for traction.

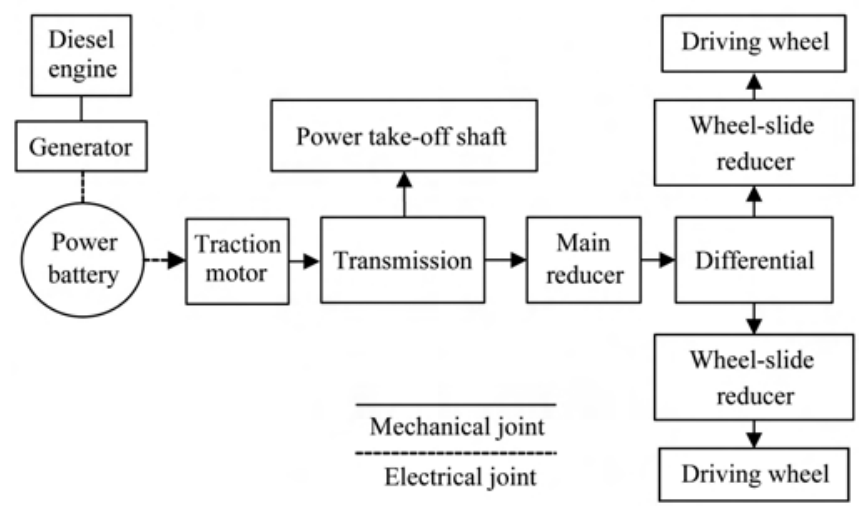

Figure 2 Power flow in pure electric drive mode

Figure 3 shows the power flow in extended-range mode. The tractor works in this mode when the power battery's SOC is lower than its minimum threshold, based on the energy management strategy. The diesel engine's mechanical power is transformed into electrical power by the generator, and it then flows to the power battery. The other power flow is the same as the power flow in pure electric drive mode.

Power flow in parking charging mode is shown in Figure 4 . The power battery is charged by a charging pile when the tractor is not working and the power battery's SOC is relatively low. The charging pile's electrical power is transmitted to the power battery.

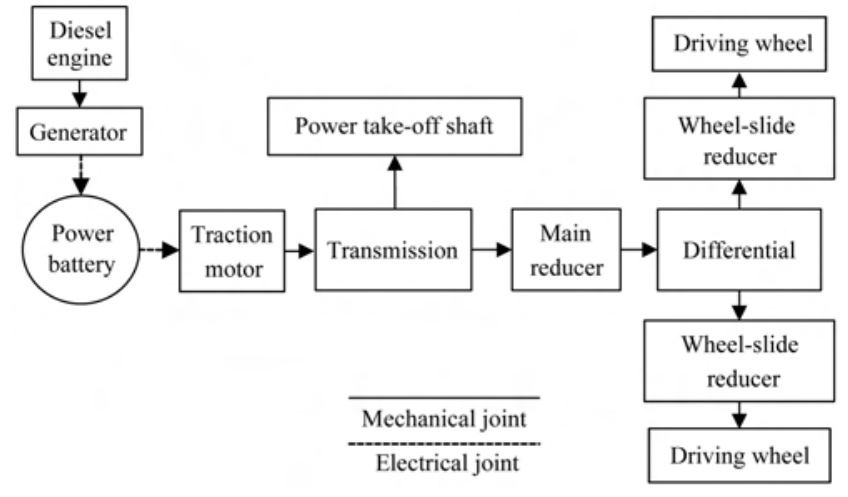

Figure 3 Power flow in extended-range mode

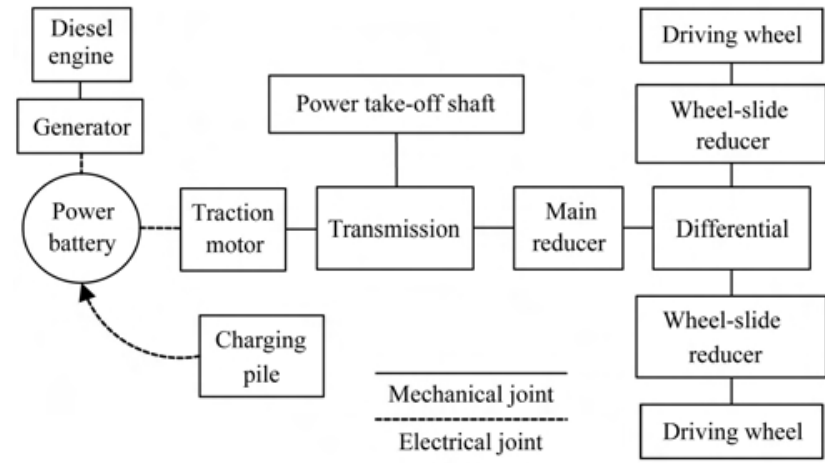

Figure 4 Power flow in parking charging mode

\section{Algorithm of control parameter adjustment}

The control parameter adjustment algorithm was designed for an ERET based on tractor ploughing operations. YTO 1LF-535 hydraulic reversible plow was adopted as the farm implement.

The tractor ploughing operation is made necessarily simple, and then divided into four stages, which are uniform acceleration, uniform velocity, uniform deceleration, and turning. The following assumptions are adopted: the acceleration at the uniform acceleration stage is the same as the deceleration at the uniform deceleration stage; the distances of the four stages in a single-way, which represents a circulation from the beginning to the end, are all of fixed value.

The available capacity of the power battery in pure electric drive mode is expressed in Equation (1):

$$
\Delta c=c_{0}\left(S O C_{\mathrm{t}}-S O C_{\mathrm{L}}\right)
$$

where, $\Delta c$ is the available capacity of the power battery, $\mathrm{A} \cdot \mathrm{h} ; c_{0}$ is the capacity of the power battery, $\mathrm{A} \cdot \mathrm{h} ; S O C_{\mathrm{t}}$ is the SOC of the power battery when the proposed strategy is going to work, $\% ; S O C_{\mathrm{L}}$ is the desired threshold of the SOC when the engine starts to work, $\%$.

The available energy of the power battery in pure electric drive mode is expressed in Equation (2): 


$$
q=u_{0} \Delta c \times 10^{-3}
$$

where, $q$ is the available energy of the power battery, $\mathrm{kW} \cdot \mathrm{h} ; u_{0}$ is its nominal voltage, $\mathrm{V}$.

The energy distribution in pure electric drive mode is expressed in Equation (3):

$$
q=\left(\frac{W}{\eta}+W_{\mathrm{F}}\right) \times \frac{1}{3.6} \times 10^{-6}
$$

where, $W$ is the energy consumption of the tractor when overcoming traction resistance, rolling resistance, acceleration resistance, and gradient resistance, $\mathrm{J} ; \eta$ is the efficiency of energy utilization of the transmission system; $W_{\mathrm{F}}$ is the energy consumption of the tractor's accessories, J.

The efficiency of energy utilization of the tractor transmission system is expressed in Equation (4):

$$
\eta=\eta_{\mathrm{b}} \eta_{\mathrm{m}} \eta_{\mathrm{c}} \eta_{\mathrm{t}} \delta
$$

where, $\eta_{\mathrm{b}}$ is the discharge efficiency of the power battery; $\eta_{\mathrm{m}}$ is the efficiency of the traction motor; $\eta_{\mathrm{c}}$ is the efficiency of the traction motor's controller; $\eta_{t}$ is the efficiency of the transmission system; $\delta$ is the slip efficiency of the driving wheel.

By analyzing the tractor's ploughing operation, the energy consumption of the tractor can be expressed as Equation (5):

$$
W=W_{1}+W_{2}+W_{3}+W_{4}
$$

where, $W_{1}$ is the energy consumption during the uniform acceleration stage, $\mathrm{J} ; W_{2}$ is the energy consumption during the uniform velocity stage, $\mathrm{J} ; W_{3}$ is the energy consumption during the uniform deceleration stage, $\mathrm{J} ; W_{4}$ is the energy consumption during the turning stage, $\mathrm{J}$; all of them exclude the energy consumption of accessories.

The energy consumption of the tractor at each stage is expressed in Equation (6):

$$
W_{\mathrm{n}}=\left\{\begin{array}{cc}
\left(F_{\mathrm{a}}+F_{\mathrm{T}}+F_{\mathrm{f}}+F_{\mathrm{i}}\right) d_{1}, & n=1 \\
\left(F_{\mathrm{T}}+F_{\mathrm{f}}+F_{\mathrm{i}}\right) d_{2}, & n=2 \\
\left(F_{\mathrm{T}}+F_{\mathrm{f}}+F_{\mathrm{i}}-F_{\mathrm{a}}\right) d_{3}, & n=3 \\
\left(F_{\mathrm{f}}+F_{\mathrm{i}}\right) d_{4}, & n=4
\end{array}\right.
$$

where, $F_{\mathrm{a}}$ is the acceleration resistance, N; $F_{\mathrm{T}}$ is the ploughing resistance, $\mathrm{N} ; F_{\mathrm{f}}$ is the rolling resistance, $\mathrm{N} ; F_{\mathrm{i}}$ is the gradient resistance, $\mathrm{N} ; d_{1}$ is the distances of the uniform acceleration stage, $\mathrm{m} ; d_{2}$ is the distances of the uniform velocity stage, $\mathrm{m} ; d_{3}$ is the distances of the uniform deceleration stage, $\mathrm{m} ; d_{4}$ is the distances of the turning stage, $\mathrm{m}$.

Based on Equations (5) and (6), it is can be deduced as

$$
\left\{\begin{array}{l}
W=\alpha F_{\mathrm{T}}\left(d_{1}+d_{2}+d_{3}\right) \\
\alpha=1+\left(\frac{F_{\mathrm{f}}}{F_{\mathrm{T}}}+\frac{F_{\mathrm{i}}}{F_{\mathrm{T}}}\right) \frac{d_{1}+d_{2}+d_{3}+d_{4}}{d_{1}+d_{2}+d_{3}}
\end{array}\right.
$$

In order to illustrate easily, $\alpha$ is set as in Equation (7).

The ploughing resistance of the tractor is

$$
F_{\mathrm{T}}=Z b_{\mathrm{n}} k_{0} h
$$

where, $Z$ is the number of plowshares; $b_{\mathrm{n}}$ is the width of a single plowshare, $\mathrm{cm} ; k_{0}$ is the soil-specific resistance, $\mathrm{N} / \mathrm{cm}^{2} ; h$ is the depth of ploughing, $\mathrm{cm}$. The soil-specific resistance is assumed as constant value.

The working distances of the tractor's stages are

$$
d_{\mathrm{m}}=\frac{S \times 666.7}{Z b_{\mathrm{n}} l} d_{\mathrm{m} 0}, m=1,3,4
$$

where, the constants $d_{\mathrm{m} 0}$ are the single-way distances of the tractor's stages, $\mathrm{m}$; ( $d_{10}$ is the single-way distances of the uniform acceleration stage, $d_{30}$ is the single-way distances of the uniform deceleration stage, and $d_{40}$ is the single-way distances of the turning stage); $S$ is the operation area of the tractor, $\mathrm{mu},\left(1 \mathrm{mu}=666.7 \mathrm{~m}^{2}\right) ; l$ is the farmland length, $\mathrm{m}$.

The working distance of the tractor's uniform velocity stage is

$$
d_{2}=\frac{S \times 666.7}{Z b_{\mathrm{n}} l} \times\left(l-d_{10}-d_{30}\right)
$$

Based on Equations (1)-(10), under the condition that the tractor absolutely works in pure electric drive mode, control model can be established by

$$
\left\{\begin{array}{l}
S O C_{\mathrm{L}}=S O C_{\mathrm{t}}-\frac{k_{0} S \beta h}{u_{0} c_{0}} \times 0.1852 \\
\beta=\frac{\alpha}{\eta}+\frac{W_{\mathrm{F}}}{F_{\mathrm{T}}\left(d_{1}+d_{2}+d_{3}\right)}
\end{array}\right.
$$

In order to illustrate easily, set $\beta$ as in Equation (11). In this paper, $Z$ is equal to $5, b_{\mathrm{n}}$ is equal to $45 \mathrm{~cm}, k_{0}$ is equal to 7.

\section{Energy management strategy}

To reduce fuel consumption, an energy management strategy was proposed for the control parameter adjustment (EMSCPA) in an ERET in this paper. In order to test the proposed strategy, the FPEMS is set as the contrast. 
4.1 Diesel engine start and stop control plus fixed point energy management strategy

For diesel engine start and stop control, the diesel engine starts when the power battery's SOC is lower than the minimum threshold $\mathrm{SOC}_{\mathrm{L}}$ and it shuts down when the power battery's SOC is higher than its maximum threshold $\mathrm{SOC}_{\mathrm{H}}$. When the power battery's $\mathrm{SOC}$ is between the maximum and minimum thresholds, the diesel engine stays in current state. The diesel engine start and stop control is shown in Figure 5. For the fixed point energy management strategy, the diesel engine works at constant power after the diesel engine starts. After theoretical analysis and simulation test, the proportional, the integral and the differential of the PID controller used in this case are respectively set as 20 , 0.0002 and 0.0025 .

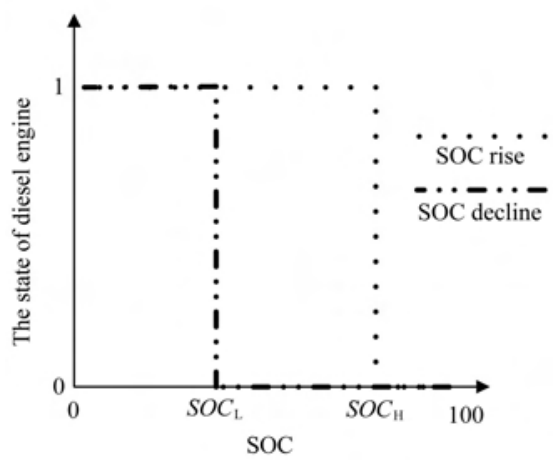

Figure 5 Control of engine start-stop

\subsection{Energy management strategy of control parameter adjustment}

The EMSCPA proposed in this paper is based on the FPEMS. It is simple and easy to use in practice. Based on the improvement of the FPEMS, the utilization of electrical energy of the battery was improved, and the working time of the diesel engine decreased. The diesel engine worked at constant power after the diesel engine started. The control of the diesel engine was the same as the diesel engine start and stop control plus fixed point energy management strategy. The power distribution strategy is expressed in Equation (12):

$$
P_{\mathrm{T}}=\left\{\begin{array}{l}
P_{\mathrm{bT}} \eta, \quad \varphi(t)=0 \\
\left(P_{\mathrm{eT}}+P_{\mathrm{bT}}\right) \eta, \varphi(t)=1
\end{array}\right.
$$

where, $P_{\mathrm{T}}$ is the power required to drive a tractor, $\mathrm{kW}$; $P_{\mathrm{bT}}$ is the discharge power of the power battery in the case of consuming its own energy, $\mathrm{kW} ; P_{\mathrm{eT}}$ is the power of the range extender, $\mathrm{kW} ; \varphi(t)$ is the state of the diesel engine. The diesel engine works when $\varphi(t)$ is equal to one, and it shuts down when $\varphi(t)$ is equal to zero.

The start and stop control of the diesel engine is expressed in Equation (13):

$$
\varphi(t)=\left\{\begin{array}{cc}
0, & S O C_{\mathrm{t}}>\mathrm{SOC}_{\mathrm{H}} \\
1, & S O C_{\mathrm{t}}<S O C_{\mathrm{L}} \\
\lim _{\Delta \rightarrow 0} \varphi(t-\Delta), S O C_{\mathrm{L}} \leq S O C_{\mathrm{t}} \leq \mathrm{SOC}_{\mathrm{H}}
\end{array}\right.
$$

where, $S O C_{\mathrm{H}}$ is a constant. $S O C_{\mathrm{L}}$ depends on the algorithm of the control parameter adjustment.

Based on Equation (11), when $S O C_{\mathrm{L}}$ is set to zero, the following expression can be obtained:

$$
S \beta h=\frac{u_{0} c_{0}}{0.1852 k_{0}} S O C_{\mathrm{t}}
$$

where, $A$ is set to represent the right part of Equation (14), that is, $A=\frac{u 0 c 0}{0.1852 k 0} S O C_{\mathrm{t}}$.

Based on Equation (11), when $S O C_{\mathrm{L}}$ is set to $15 \%$, it can be obtained that

$$
S \beta h=\frac{u_{0} c_{0}}{0.1852 k_{0}}\left(S O C_{\mathrm{t}}-5 \%\right)
$$

where, $B$ is set to represent the right part of Equation (15), that is, $B=\frac{u_{0} c_{0}}{0.1852 k_{0}}\left(S O C_{\mathrm{t}}-5 \%\right)$.

The control diagram of parameter adjustment is shown in Figure 6. First, the driver inputs the operation area, farmland's length, and ploughing depth. The controller, which includes the drive control system and

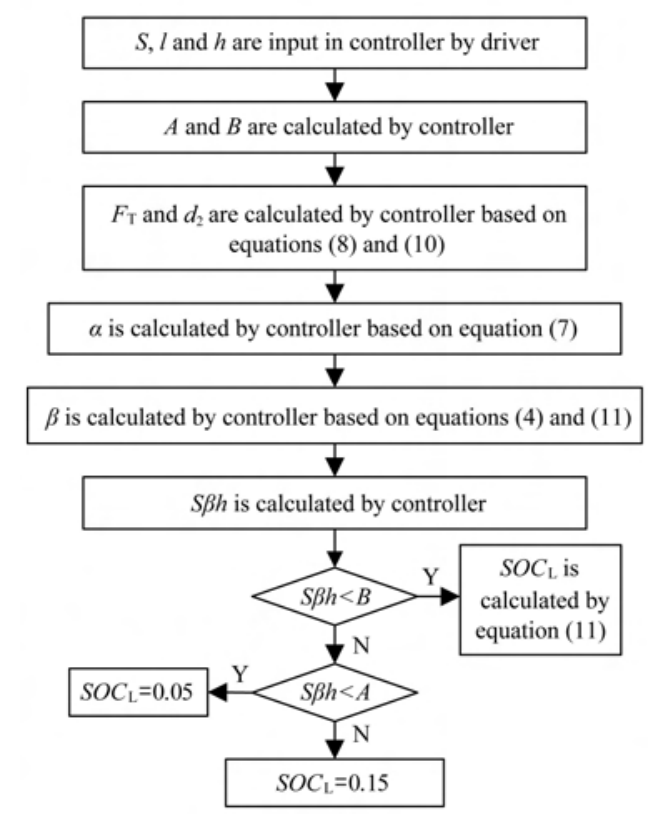

Figure 6 Control flow diagram of control parameter adjustment 
the extended-range control in the AVL-Cruise simulation software, calculates $S \beta h, B$ and $A$. The comparison is then implemented among them. It indicates that the energy required by the tractor can be supplied fully by the power battery under the condition that $S \beta h$ is smaller than $B$. And at the moment, the value of $S O C_{\mathrm{L}}$ is taken based on Equation (11). It means that the energy required by the tractor can still be offered exclusively by the power battery under the condition that $S \beta h$ is between $A$ and $B$. But, to guarantee the tractor can still continually work when the diesel engine and generator can't work, the value of $S O C_{\mathrm{L}}$ is set to 0.05 . Otherwise, the value of $S O C_{\mathrm{L}}$ is set to 0.15 .

Based on the previous research ${ }^{[10]}$, the simulation model of the ERET is established. The simulation model is shown in Figure 7.

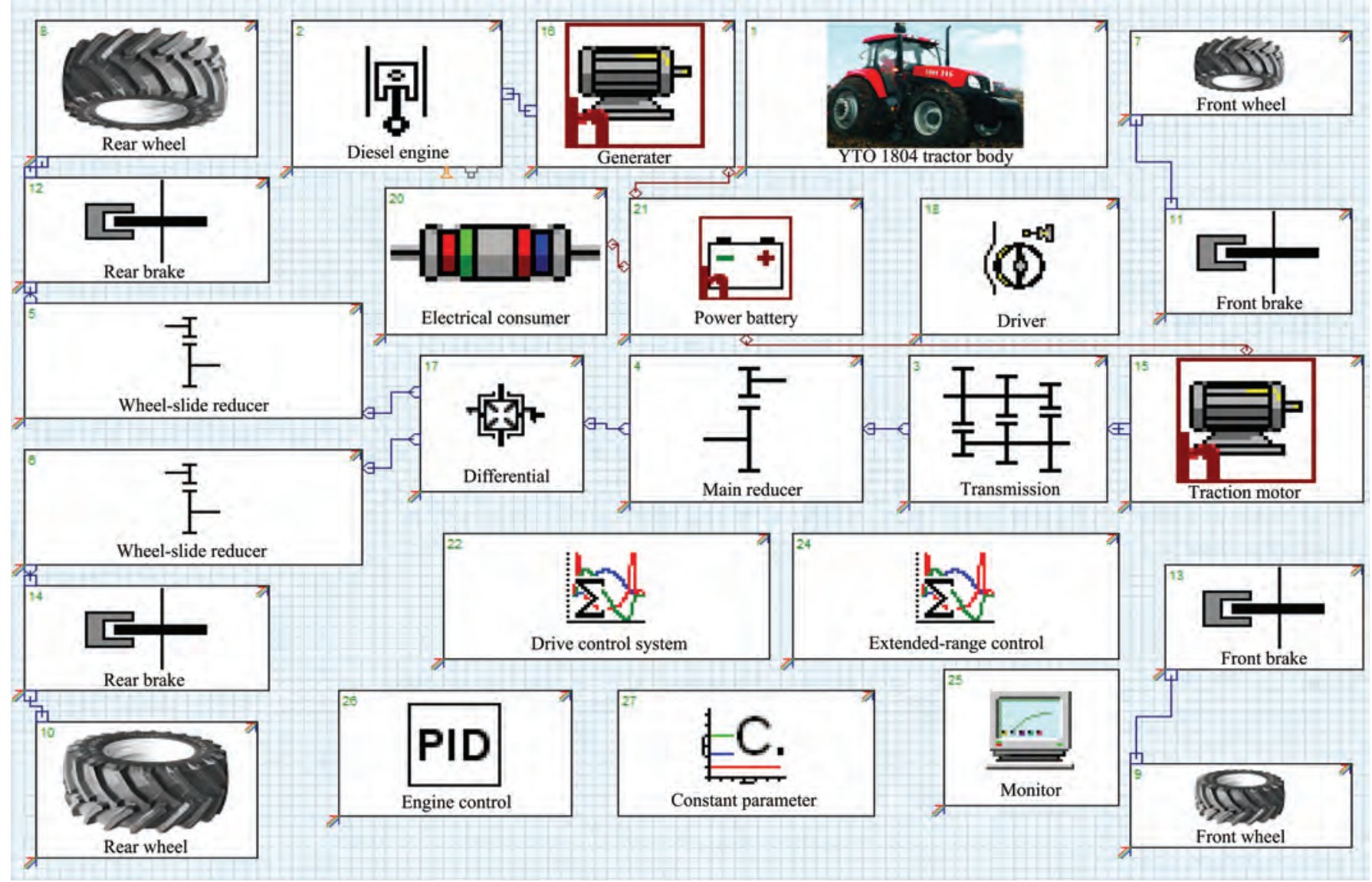

Figure 7 Simulation model of ERET

\section{Simulation validation and analysis}

Simulations are very important to verify the performance of the proposed strategy. In this study, the AVL-Cruise simulation software program was adopted to establish a simulation model and energy management strategy of an ERET, the performance of the proposed strategy was tested in different conditions and compared with the FPEMS.

\subsection{Working condition}

To verify the applicability of the EMSCPA, two conditions are set, which are the continuous transfer operation and the small area deep loosening operation. The ETET's running diagrams about continuous transfer operation and small area deep loosening operation are shown in Figures $8 \mathrm{a}$ and $8 \mathrm{~b}$, respectively.

The transfer distances were set to $500 \mathrm{~m}$ for the farmlands showed in Figures 8a. The single-way distance of the turning stage was set to $10.5 \mathrm{~m}$. And the turning stage distances of farmlands 1, 2, 3 and 4 were set as $105 \mathrm{~m}, 157.5 \mathrm{~m}, 220.5 \mathrm{~m}$ and $220.5 \mathrm{~m}$, respectively.

The relationship between velocity and time in the continuous transfer operation is shown in Figure 9, which includes the operations of the three farmlands and the transfer operation (from one to another). Figure 10 shows the relationship between velocity and time in the small area deep loosening operation. The continuous transfer operation contains uniform acceleration, uniform 
velocity, uniform deceleration, and turning stages. The small area deep loosening operation consisted of uniform acceleration, uniform velocity, uniform deceleration, and turning stages. The driver inputs the operation area, the farmland length and the depth of ploughing before working. The depths of ploughing of the continuous transfer operation and the small area deep operation were set to $25 \mathrm{~cm}$ and $30 \mathrm{~cm}$, respectively, in this study.


Figure 8 Running diagram of ERET

b. Small area deep loosening operation

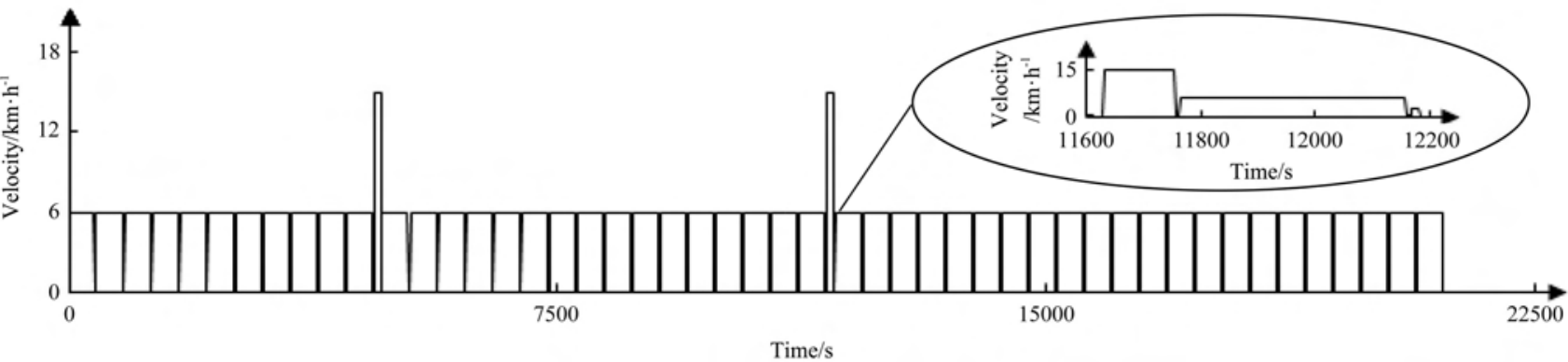

Figure 9 Tractor velocity following the continuous transfer operation



Figure 10 Tractor velocity following the small area deep loosening operation

\subsection{Simulation results and analysis}

Two working conditions were designed to compare the performances of FPEMS and EMSCPA.

For the continuous transfer operation, Figure 11 shows the simulation results of fuel consumption rate and cumulative fuel consumption controlled by the FPEMS and EMSCPA respectively. In Figure 11, it can be found that, the diesel engine outputting constant power continued for $7838 \mathrm{sec}$ under the FPEMS. When it enters extended-range mode, the diesel engine's fuel consumption rate reaches $22.328 \mathrm{~L} / \mathrm{h}$. When the time reaches $21108 \mathrm{~s}$, the diesel engine's cumulative fuel consumption runs up to $82.307 \mathrm{~L}$. Under the EMSCPA, the diesel engine starts and works at a constant power at the time of $16567 \mathrm{~s}$, and when the ERET enters extended-range mode, its fuel consumption rate is around $22.328 \mathrm{~L} / \mathrm{h}$. At $21108 \mathrm{~s}$, the diesel engine's cumulative fuel consumption comes to $28.166 \mathrm{~L}$.

Figure 12 shows the simulation results of the SOC of power battery and the electrical consumption using the FPEMS and EMSCPA respectively. Under the FPEMS, the power battery's initial SOC value is $80 \%$. At $7838 \mathrm{~s}$ the SOC goes down to $50 \%$, and later it goes down, following a lower slope. At $21108 \mathrm{~s}$ the power battery's SOC decreases to $31.36 \%$ and the electrical consumption reaches $398.036 \mathrm{~kW} \cdot \mathrm{h}$. Under the 
EMSCPA, the power battery's initial SOC value is still $80 \%$. At $16567 \mathrm{~s}$ the SOC decreases to $15 \%$, and later it decreases, following a lower slope. At $21108 \mathrm{~s}$ the power battery's SOC decreases to $8.3 \%$ and the electrical consumption rises to $561.932 \mathrm{~kW} \cdot \mathrm{h}$.

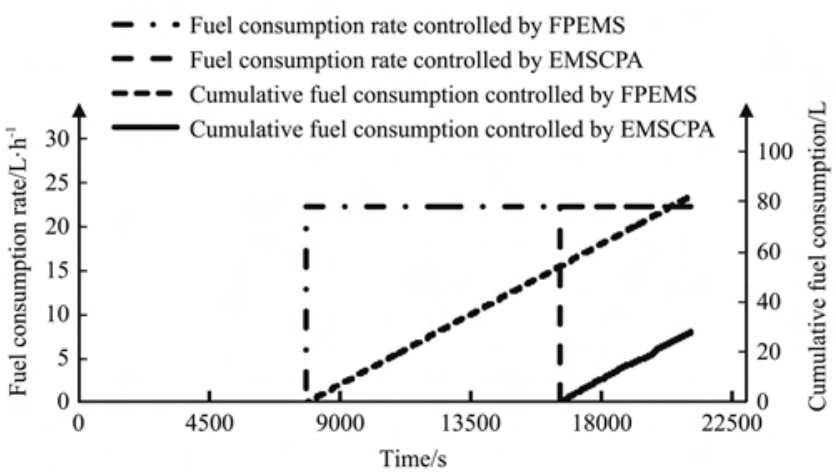

Figure 11 Fuel consumption rates and cumulative fuel consumptions of the two strategies under the continuous transfer operation

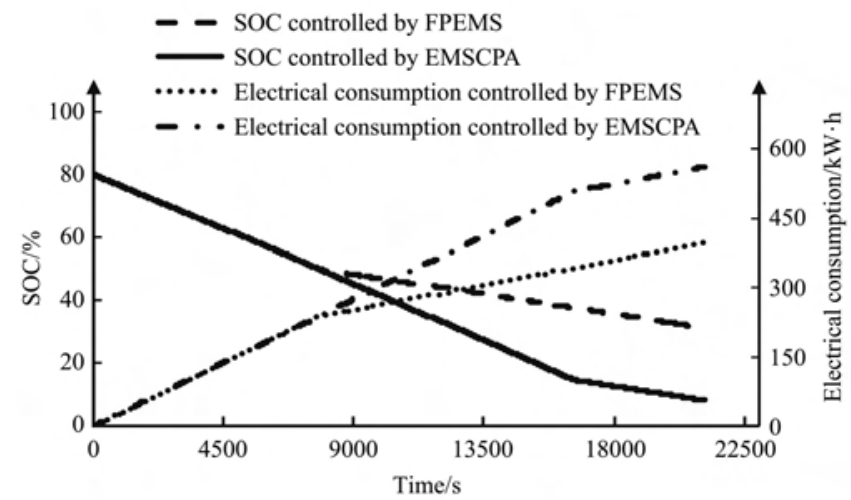

Figure 12 SOCs and electrical consumption of the two strategies under the continuous transfer operation

The simulation results of the power battery's discharge power controlled by the FPEMS and EMSCPA are shown in Figure 13 and Figure 14 respectively. And it is can be known that the power battery's discharge is steady. In Figure 13, the power battery's discharge power decreases obviously after $7838 \mathrm{~s}$. And the time is $16567 \mathrm{~s}$ in Figure 14.

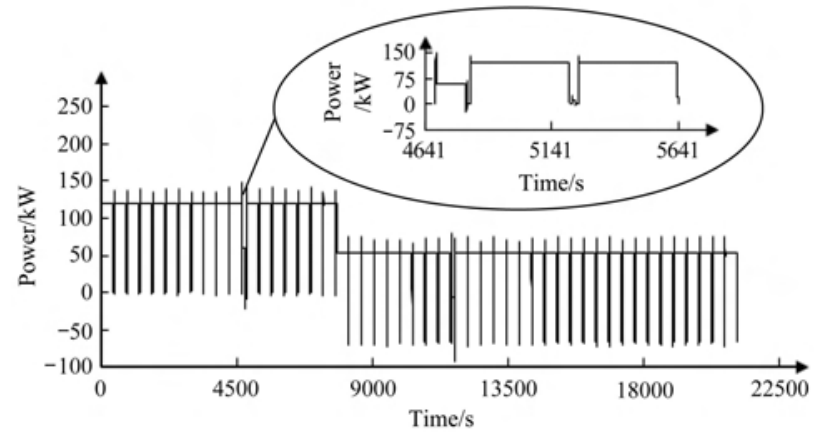

Figure 13 Discharge power of power battery using FPEMS under the continuous transfer operation

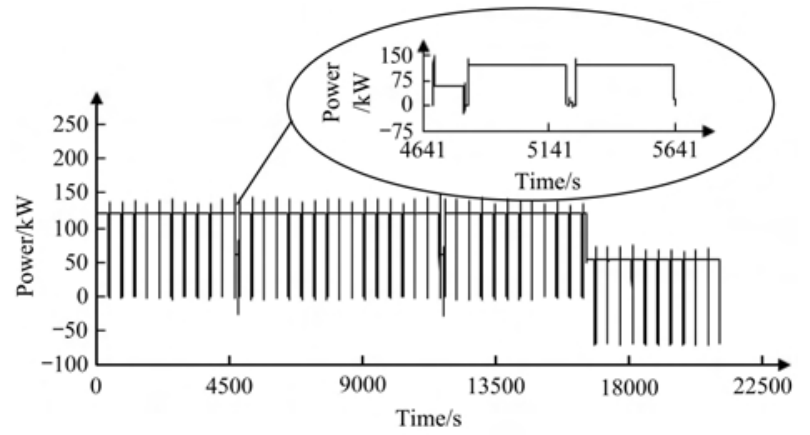

Figure 14 Discharge power of power battery adopting EMSCPA under the continuous transfer operation

The above simulation results show that under the continuous transfer operation, the cumulative fuel consumption using the EMSCPA is $34.22 \%$ of the cumulative fuel consumption employing the FPEMS. The electrical consumption adopting the FPEMS is $70.83 \%$ of the electrical consumption conducting the EMSCPA.

For the small area deep loosening operation, Figure 15 shows the simulation results of fuel consumption rate and cumulative fuel consumption employing the FPEMS. Under the FPEMS, the diesel engine starts and works at a constant power at the time of $4061 \mathrm{~s}$, and the diesel engine's fuel consumption rate is around $22.328 \mathrm{~L} / \mathrm{h}$. At $9346 \mathrm{~s}$, the diesel engine's cumulative fuel consumption reaches $32.781 \mathrm{~L}$.

The simulation results of the power battery's SOC and the electrical consumption controlled by the FPEMS and EMSCPA respectively are shown in Figure 16. Under the FPEMS, the power battery's initial SOC value is $70 \%$. The SOC decreases to $50 \%$ when the time reaches 4061 s. Later it goes down, following a lower slope. And at $9346 \mathrm{~s}$, the power battery's SOC decreases to $38.30 \%$ and electrical consumption increases to $247.638 \mathrm{~kW} \cdot \mathrm{h}$. Under the EMSCPA, the power battery's initial SOC value is $70 \%$, and the tractor operates in pure electric drive mode on the whole course. When the time reaches $9346 \mathrm{~s}$, the power battery's SOC value reduces to $23.02 \%$, and the electrical consumption adds up to $346.868 \mathrm{~kW} \cdot \mathrm{h}$.

Figure 17 shows the simulation results of the discharge power of the power battery with the FPEMS. Figure 18 shows the simulation results of the discharge power of the power battery with the EMSCPA. It is can be found from Figures 17 and 18 that the power battery's discharge is steady. In Figure 17, the power battery's discharge power decreases obviously after $4061 \mathrm{~s}$. 




Figure 15 Fuel consumption rate and cumulative fuel consumption of FPEMS under the small area deep loosening operation

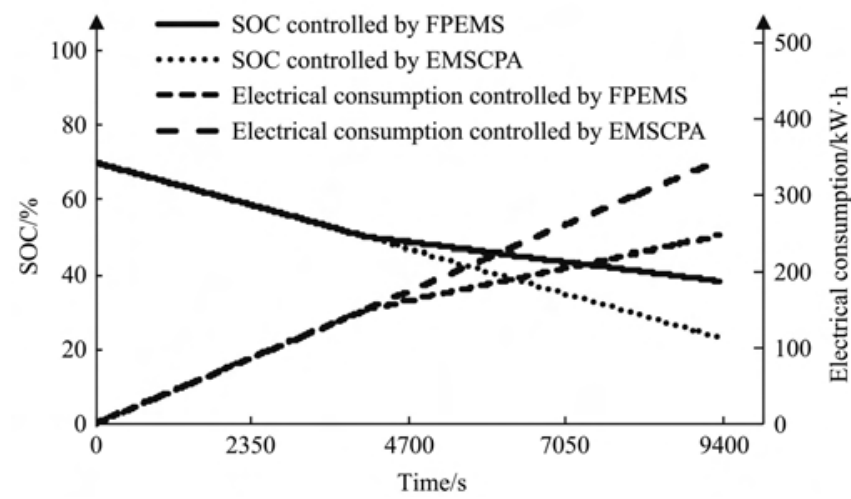

Figure 16 SOCs and electrical consumptions of the two strategies under the small area deep loosening operation

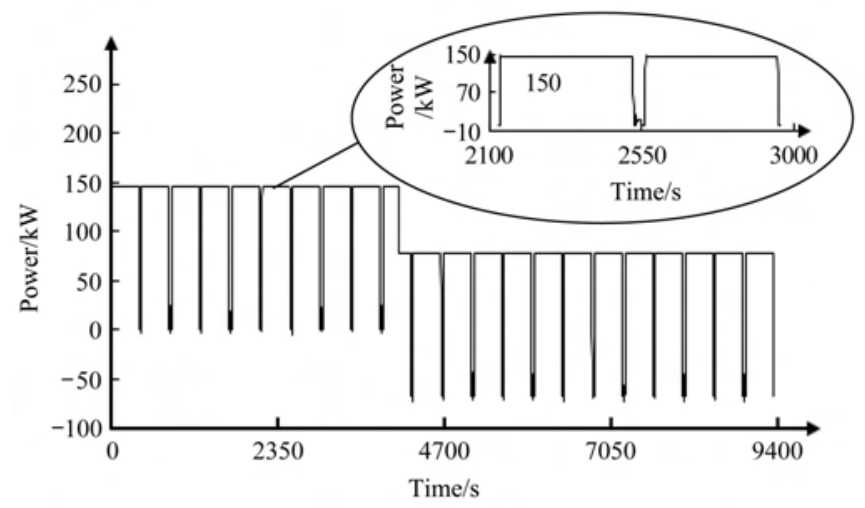

Figure 17 Discharge power of power battery using FPEMS under the small area deep loosening operation

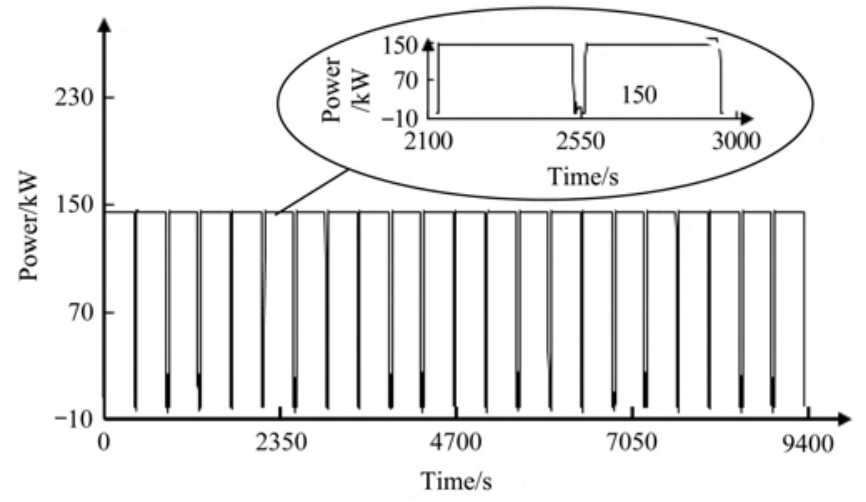

Figure 18 Discharge power of power battery using EMSCPA under the small area deep loosening operation
The above simulation results show that under the conditions of the small area deep loosening operation, the tractor works in pure electric drive mode using the EMSCPA, and the tractor does not consume fuel. Cumulative fuel consumption implementing the FPEMS is $32.781 \mathrm{~L}$. And the electrical consumption conducting the EMSCPA increases $40.08 \%$, compared to the electrical consumption employing FPEMS.

\section{Conclusions}

In this paper, a control parameter adjustment algorithm for the energy management of an ERET was proposed for reducing the fuel consumption and enhancing consumption from the power battery, which requires parameters of the operation area, the farmland length and the depth of ploughing input by the driver. Based on the algorithm, EMSCPA has been designed. This paper analyzes the energy consumption with the proposed strategy and FPEMS, under two operations.

Simulation results from two operations show that the proposed strategy has good applicability. Simulation results show a significant reduction in fuel consumption under the proposed strategy, compared with the FPEMS. Under the continuous transfer operation, the fuel consumption controlled by the proposed strategy is $34.22 \%$ of the fuel consumption controlled by the FPEMS; the electrical consumption controlled by the FPEMS is $70.83 \%$ of the electrical consumption controlled by the EMSCPA. Under the small area deep loosening operation, the tractor works purely in electric drive mode implementing the proposed strategy, while the fuel consumption is $32.781 \mathrm{~L}$ executing the FPEMS; the electrical consumption carrying out the proposed strategy increases $40.08 \%$ over that of the FPEMS.

The algorithm of the control parameter adjustment provides a theoretical basis for developing a more energy-saving energy management strategy of an ERET.

\section{Acknowledgements}

This work was supported by the National Key Research and Development Program of China during the 13th Five-Year Plan Period (No. 2016YFD0701002), Henan University of Science and Technology Innovation 
Talents Support Program (No. 18HASTIT026), and Research Program of Application Foundation and Advanced Technology of Henan Province (No. $152300410080)$.

\section{[References]}

[1] Lee J W, Kim J S, Kim K U. Computer simulations to maximise fuel efficiency and work performance of agricultural tractors in rotovating and ploughing operations. Biosystems Engineering, 2016; 142: 1-11.

[2] Pitla S K, Luck J D, Werner J, Lin N, Shearer S A. In-field fuel use and load states of agricultural field machinery. Computers and Electronics in Agriculture, 2016; 121: 290-300.

[3] Lee D-H, Choi C-H, Chung S-O, Kim Y-J, Inoue E, Okayasu T. Evaluation of tractor fuel efficiency using dynamometer and baler operation cycle. Journal of the Faculty of Agriculture Kyushu University, 2016; 61(1): 173-182.

[4] Juostas A, Janulevičius A. Tractor's engine efficiency and exhaust emissions' research in drilling work. Journal of Environmental Engineering and Landscape Management, 2014; 22(2): 141-150.

[5] Janulevičius A. Juostas A, Pupinis G. Tractor's engine performance and emission characteristics in the process of ploughing. Energy Conversion and Management, 2013; 75: 498-508.

[6] Lee J-S, Kim S T, Cao R., Choi N-S, Liu M, Lee K T, et al. Metal-air batteries with high energy density: Li-air versus Zn-air. Advanced Energy Materials, 2011; 1(1): 34-50.

[7] Burke A F. Batteries and ultracapacitors for electric, hybrid, and fuel cell vehicles. Proceedings of the IEEE, 2007; 95(4): 806-820.

[8] Yoshida K, Tomonari S, Yoshioka H, Tanaka S, Satoh D, Esashi M. High energy density miniature electrical and thermal power source using catalytic combustion of butane. The 17th IEEE International Conference on Micro Electro Mechanical Systems (MEMS '04), Kyoto, Japan, 2004; pp. 316-321.

[9] Pollet B G, Staffell L, Shang J L. Current status of hybrid, battery and fuel cell electric vehicles: From electrochemistry to market prospects. Electrochimica Acta, 2012; 84: 235-249.

[10] Liu M N, Xu L Y, Zhou Z L, Liu W. Establishment of extended range electric tractor and its rotary cultivator's simulative platforms. China Mechanical Engineering, 2016; 27(3): 413-419.

[11] Miller M, Holmes A, Conlon B, Savagian P. The GM "Voltec" 4ET50 multi-mode electric transaxle. SAE Int. J. Engines, 2011; 4(1): 1102-1114.

[12] Zhou S, Niu J G, Chen F X, Pei F L. A study on powertrain design and simulation for range-extended electric vehicle. Automotive Engineering, 2011; 33(11): 924-929. (in Chinese)

[13] Wen J, Chen Y. Parameter matching and simulation study on powertrain for extended-range electric school bus. Computer Simulation, 2015; 32(10): 172-176. (in Chinese)

[14] Kuang Y H, Zhang Y J, Zhou B, Li C B, Cao Y J, Li L J et al. A review of renewable energy utilization in islands. Renewable and Sustainable Energy Reviews, 2016; 59: 504-513.

[15] Zhou B Y, Wu Y, Zhou B, Wang R J, Ke W W, Zhang S J, et al. Real-world performance of battery electric buses and their life-cycle benefits with respect to energy consumption and carbon dioxide emissions. Energy, 2016; 96: 603-613.

[16] Torres J L, Gonzalez R, Gimenez A, Lopez J. Energy management strategy for plug-in hybrid electric vehicles: A comparative study. Applied Energy, 2014; 113: 816-824.

[17] Tie S F, Tan C W. A review of energy sources and energy management system in electric vehicles. Renewable and Sustainable Energy Reviews, 2013; 20: 82-102.

[18] Ansarey M, Panahi M S, Ziarati H, Mahjoob M. Optimal energy management in a dual-storage fuel-cell hybrid vehicle using multi-dimensional dynamic programming. Journal of Power Sources, 2014; 250: 359-371.

[19] Hou C, Ouyang M G, Xu L F, Wang H W. Approximate Pontryagin's minimum principle applied to the energy management of plug-in hybrid electric vehicles. Applied Energy, 2014; 115: 174-189.

[20] Nuesch T, Cerofolini A, Mancini G, Cavina N, Onder C, Guzzella L. Equivalent consumption minimization strategy for the control of real driving NOx emissions of a diesel hybrid electric vehicle. Energies, 2014; 7(5): 3148-3178.

[21] Chen Z, Mi C C, Xiong R, Xu J, You C W. Energy management of a power-split plug-in hybrid electric vehicle based on genetic algorithm and quadratic programming. Journal of Power Sources, 2014; 248: 416-426.

[22] Chen B-C, Wu Y-Y, Tsai H-C. Design and analysis of power management strategy for range extended electric vehicle using dynamic programming. Applied Energy, 2014; 113: 1764-1774.

[23] Kelouwani S, Henao N, Agbossou K. Two-layer energy-management architecture for a fuel cell HEV using road trip information. IEEE Transactions on Vehicular Technology, 2012; 61(9): 3851-3864.

[24] Chen Z, Zhang X, Mi C C. Slide mode and fuzzy logic based powertrain controller for the energy management and battery lifetime extension of series hybrid electric vehicles. Journal of Asian Electric Vehicles, 2010; 8: 1425-1432.

[25] Banvait H, Anwar S, Chen Y. A rule-based energy management strategy for plug-in hybrid electric vehicle (PHEV). In Proceedings of the American Control Conference, MO, USA, 2009; pp. 3938-3943. 